\title{
Correction: Fluorescent carbon dots from mono- and polysaccharides: synthesis, properties and applications
}

\author{
Stephen Hill and M. Carmen Galan*
}

\section{Correction}

Address:

School of Chemistry, University of Bristol, Cantock's Close, Bristol BS8 1TS, UK

\section{Email:}

M. Carmen Galan* - m.c.galan@bristol.ac.uk

* Corresponding author

Keywords:

fluorescent carbon dots; monosaccharides; nanomaterials;

nanotechnology applications; polysaccharides
Beilstein J. Org. Chem. 2017, 13, 1136-1138.

doi:10.3762/bjoc. 13.112

Received: 19 May 2017

Accepted: 02 June 2017

Published: 13 June 2017

Guest Editor: A. Hoffmann-Röder

(C) 2017 Hill and Galan; licensee Beilstein-Institut.

License and terms: see end of document.

This correction refers to Beilstein J. Org. Chem. 2017, 13, 675-693. doi:10.3762/bjoc.13.67

Our original publication showns some errors in the structures in Schemes 9, 15, 20, and 22. The corrected schemes are shown in this Correction.

The wrong configuration was depicted for $\mathrm{C}-4$ (carrying the $\mathrm{OH}$ group) in the pyranose ring of doxorubicin in Scheme 9; the corrected scheme (Scheme 1) is shown below:
The NH group was missing at $\mathrm{C}-2$ of the GlcNAc residues in Scheme 15; the corrected scheme (Scheme 2) is shown below:

The carbohydrate polymers in Schemes 20 and 22 were depicted as poly-peroxide with one oxygen atom too many in the repeating unit, repectively; the corrected schemes (Scheme 3 and Scheme 4) are shown below:<smiles>NCCNCC(=O)O</smiles>
hollow N/P-doped CDs green emission

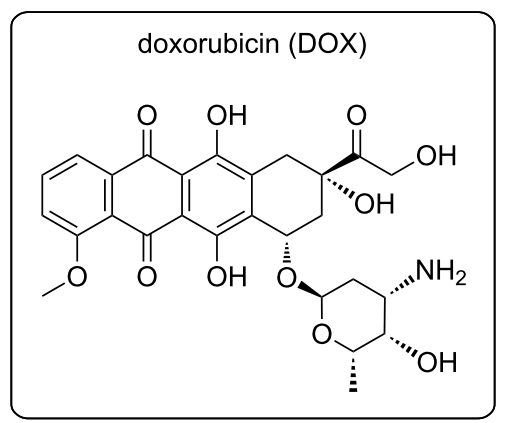




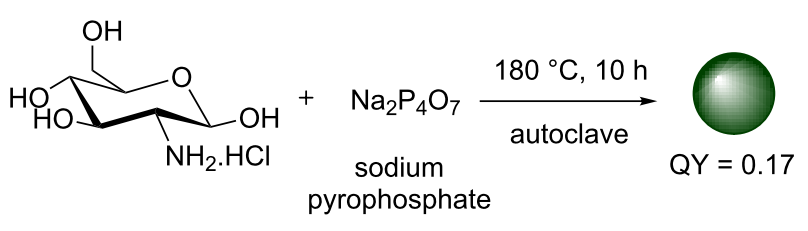
pyrophosphate

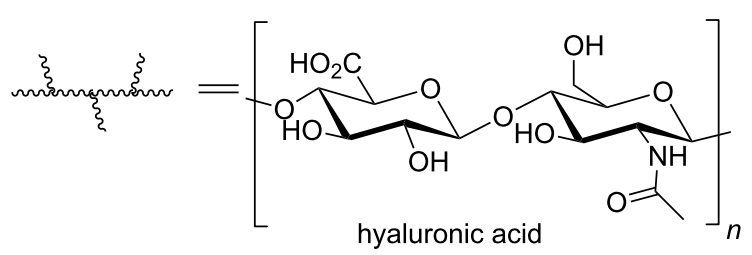

Scheme 2: Corrected Scheme 15 of the original article. N/P-doped green-emissive CDs working in tandem with hyaluronic acid-coated AuNPs to monitor hyaluronidase activity.

alginic acid
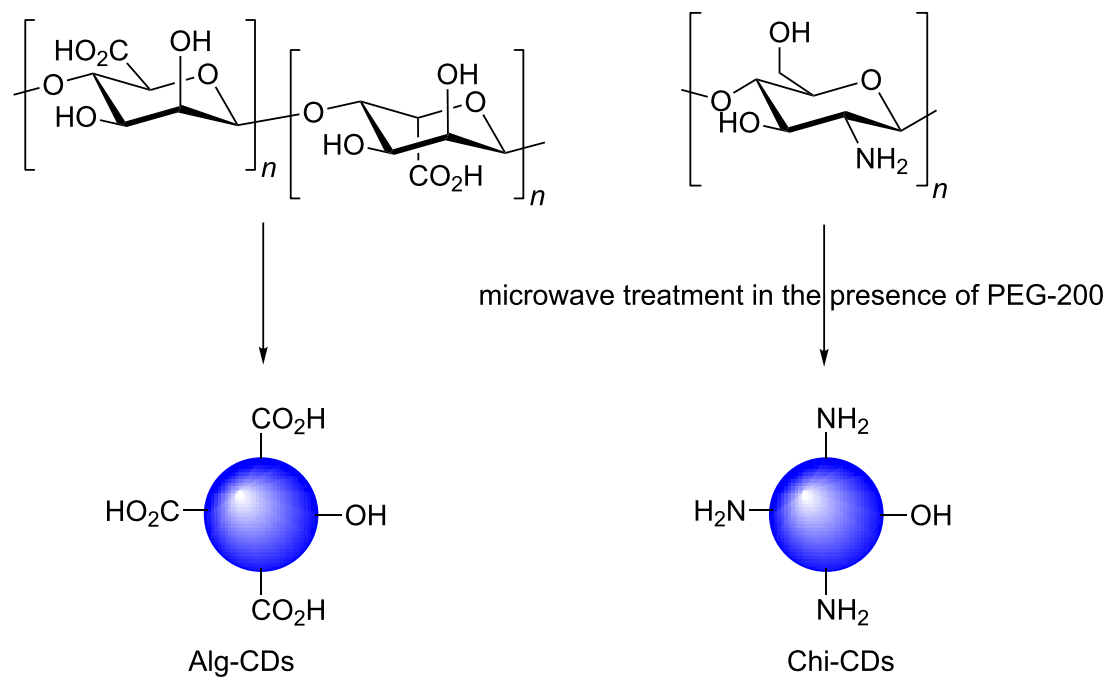

Alg-CDs chitosan

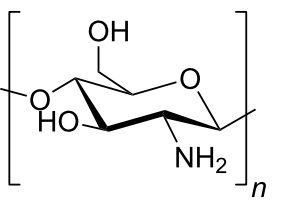

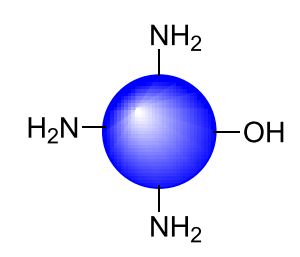

Chi-CDs
AuNP aggregation FRET overlap lost Green emission

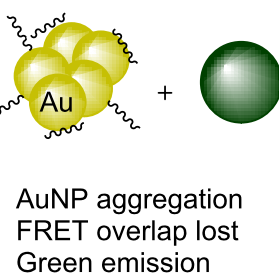

starch (amylose)
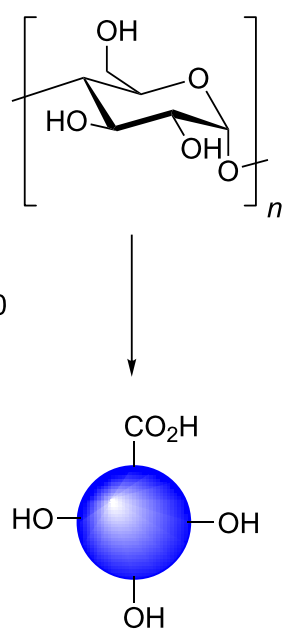

S-CDs

Scheme 3: Corrected Scheme 20 of the original article. Different polysaccharide-derived CDs in the presence of PEG-200 and how the starting material composition is conferred to the CD products.

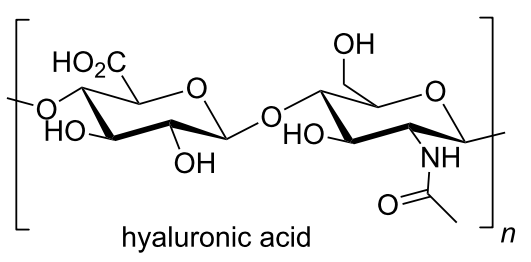

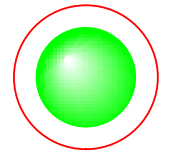

HA-decorated CDs

Scheme 4: Corrected Scheme 22 of the original article. Hyaluronic acid (HA) and glycine-derived CDs, suspected to be decorated in unreacted HA, allowing receptor-mediated cell uptake. 


\section{License and Terms}

This is an Open Access article under the terms of the Creative Commons Attribution License

(http://creativecommons.org/licenses/by/4.0), which permits unrestricted use, distribution, and reproduction in any medium, provided the original work is properly cited.

The license is subject to the Beilstein Journal of Organic Chemistry terms and conditions:

(http://www.beilstein-journals.org/bjoc)

The definitive version of this article is the electronic one which can be found at:

doi:10.3762/bjoc.13.112 